\title{
Incidence of gastric extubation of users in a home care program of a university hospital ${ }^{1}$
}

\author{
Larissa Kozloff Naves ${ }^{2}$ \\ Daisy Maria Rizatto Tronchin ${ }^{3}$
}

\begin{abstract}
This quantitative, prospective study, aimed to characterize the profile of users and caregivers and to measure the incidence of gastric extubation, identifying the type and the reasons for the extubation of these users in a Home Care Program of a university hospital. The population consisted of 37 subjects and the data were collected from April to August 2010. For the analysis, descriptive statistics, test of significance of $5 \%$ and calculation of indicators were adopted. It was found that $51.4 \%$ of the users were female, $67.5 \%$ in the age group $\geq 60$ years and $67.6 \%$ presented neurological diseases. Regarding the caregivers $89.2 \%$ were female and their mean age was 50.6 years. The incidence of extubation, considering 100 days of intubation, corresponded to 1.08 , with 0.26 planned and 0.82 unplanned $(p=0.009)$. These results allowed the rates to be calculated of the extubation of patients with gastric intubation for nutritional support in domicile care, providing support in establishing care and management goals for the continuous improvement of quality.
\end{abstract}

Descriptors: Gastrointestinal Intubation; Health Services Evaluation; Home Nursing; Nursing.

\footnotetext{
${ }^{1}$ Paper extracted from Master's Thesis "Avaliação da intubação gástrica dos usuários em programa de atendimento domiciliar em um hospital universitário" presented to Escola de Enfermagem, Universidade de São Paulo, Brazil.

${ }^{2}$ RN MSc, Sociedade Beneficente Israelita Brasileira Albert Einstein, Brazil.

${ }^{3}$ Free Lecturer, Associate Professor, Escola de Enfermagem, Universidade de São Paulo, Brazil.
} 


\section{Incidência de extubação gástrica dos usuários em um programa de assistência domiciliar de um hospital universitário}

Trata-se de estudo quantitativo, prospectivo, que objetivou caracterizar o perfil de usuários e cuidadores e mensurar a incidência de extubação gástrica, identificando o tipo e os motivos das extubações desses usuários, em um Programa de Assistência Domiciliar de um hospital universitário. A população foi composta por 37 sujeitos e os dados foram coletados de abril a agosto de 2010. Para a análise, adotou-se estatística descritiva, teste de significância de $5 \%$ e cálculo de indicadores. Constatou-se que $51,4 \%$ dos usuários pertenciam ao sexo feminino, $67,5 \%$ na faixa etária $\geq 60$ anos e $67,6 \%$ apresentavam doenças neurológicas. Quanto aos cuidadores, 89,2\% eram do sexo feminino e média de idade de 50,6 anos. A incidência de extubação, considerando-se 100 dias de entubação, correspondeu a 1,08; sendo 0,26 planejadas e 0,82 não planejadas $(p=0,009)$. Os achados permitiram calcular as taxas de extubações dos portadores de entubação gástrica, para aporte nutricional em assistência domiciliar, fornecendo subsídios no estabelecimento de metas assistenciais e gerenciais para a melhoria contínua da qualidade.

Descritores: Intubação Gastrointestinal; Avaliação de Serviços de Saúde; Assistência Domiciliar; Enfermagem.

\section{La incidencia de la extubación gástrica de los usuarios en el programa de atención domiciliaria en un hospital universitario}

Estudio cuantitativo, prospectivo cuyo objetivo de caracterizar el perfil de los usuarios y cuidadores y para medir la incidencia de extubación gástrica, la identificación del tipo y las causas de la extubación de estos usuarios en un Programa de Atención Domiciliaria en un hospital universitario. La muestra constó de 37 sujetos y los datos fueron colectados entre abril y agosto de 2010, según formularios. Para análisis, se adoptó estadística descriptiva, prueba de significancia $5 \%$ y cálculo de indicadores. Se observó que $51,4 \%$ de los usuarios eran mujeres, $67,5 \%$ edad $\geq 60$ años y $67,6 \%$ tenían enfermedades neurológicas. Los cuidadores $89,2 \%$ eran mujeres, edad media de 50,6 años. Incidencia de extubación, considerando 100 días de intubación, correspondió a 1.08, 0.26 con planificadas y 0.82 no planificadas $(p=0,009)$. Estos resultados permitieron calcular las tasas de extubaciones de los pacientes con intubación gástrica para el aporte nutricional en la atención domiciliaria, forneciendo subsidios para el establecimiento de las metas asistenciales y de gestión para la mejora continua de la calidad.

Descriptores: Intubación Gastrointestinal; Evaluación de Servicios de Salud; Atención Domiciliaria de Salud; Enfermería.

\section{Introduction}

The demands of the health services and of the users for reducing the length of hospitalization, the number of rehospitalizations and the costs, in the search for the humanization of care and improvement in the quality of life of the patients have led to the establishment of a new model of healthcare: home care. This model of care is defined as the provision of healthcare provided to people at in their home, encompassing promotion and prevention actions, treatment, rehabilitation, long-term and palliative care $^{(1)}$. In this sense, home care $(\mathrm{HC})$ is a care system to offer health services to individuals, regardless of age group, aiming to substitute sudden hospitalization due to an acute need for care or to prevent the need for institutional hospitalization, in order to maintain the individuals in their domiciles and communities and to favor the family remaining together ${ }^{(2-5)}$.

From the point of view of the professional team, $\mathrm{HC}$ involves the presence of a nurse, physician, physiotherapist, speech therapist, psychologist, dietician, nursing auxiliaries and technicians and other health 
workers. With regard to the nursing care, the nurse plays the role of coordinator of the nursing team, carries out the planning, the supervision, the execution or guidance of the care, according to the clinical complexity and needs of each individual. Therefore, the role of the nurse in home care is grounded in the nursing consultation, which involves the evaluation of the psychosocial and clinical status of the patient, inserted in their domiciliary reality, from which the planning of the care emerges ${ }^{(6)}$.

For this type of care, the presence of the caregiver is necessary, who is given the task of caring for another human being with some degree of physical or mental dependence and that requires assistance to perform their quotidian activities ${ }^{(7)}$. Thus, one can find the informal caregiver, generally represented by a family member who assumes an unpaid activity and becomes responsible for this, or the formal caregiver, who performs their activities for remuneration.

The therapeutic possibilities in the domicile environment are numerous and among them is gastric intubation for enteral nutrition and the administration of drugs through gastrostomy or a nasogastric tube. Gastric intubation in the home is a care practice that involves the installation, maintenance and stability of the tube, the administration of the diet and medication and the training of the caregivers or of the users themselves for the success of the therapy.

Epidemiological data show that the incidence of home enteral nutrition (HEN) in Spain is 40 patients per million inhabitants/year ${ }^{(8)}$. Prevalence data of HEN in the United States, show values of 460 patients per million inhabitants and in Great Britain of 280 cases per million inhabitants ${ }^{(9-10)}$. Home enteral nutrition is a safe and economical treatment, because it eliminates the cost of hospitalization, prevents hospital contamination and enables the users/patients to remain with their families. Furthermore, it is essential to prevent and treat macronutrient deficiencies and to improve the recovery of the individual providing the amount of nutrients compatible to the existing metabolism ${ }^{(11)}$. Currently, nutritional support in the domicile allows the successful treatment of patients with diseases, which otherwise would require prolonged or repeated hospitalizations for the correction of the nutritional alterations.

Another aspect involving HEN, concerns the training of the caregivers to perform the care inherent to the therapy, leaving the nurses to develop health education programs and actions aimed at the care process. Thus, the evaluative and educational processes in home care are indispensible to assess the quality, and parameters should exist that are able to address this aspect.
The quality of the care does not constitute an abstract attribute, but is constructed for the evaluation of care covering the analysis of the components of structure, process and outcome(12). In this concept, the structural component refers to the available resources, such as the financial budget, the human, physical and material resources, the implementation of care protocols and the organizational structure. The process component corresponds to the set of activities in the production, and in the health sector, in the relationships established between the professionals and the users, including the search for the diagnosis and the therapy. The outcome component, consists of obtaining the desirable characteristics of the products or services, depicting the effects of the care on the health of the user and the population, measuring the costs and deciding whether these are compatible with the sustainability of the organization(13).

In this scenario, one of the instruments used to monitor the quality of a service is the employment of indicators, aimed at efficiency, efficacy and the reliability of the work processes, thus constituting a practice beneficial for health evaluation. The indicators are conceptualized as a quantitative measure that can be used to monitor and evaluate the care provided to the user or the activities of a service ${ }^{(14)}$. The development of evaluation indicators for home care, in order to monitor the quality of healthcare provided to the users in this type of service, becomes a challenge for everyone involved in this growing healthcare model.

The complexity of the care for patients with gastric intubation for HEN provokes a reflection on the potential problems and complications that may be related to the profile of the patient, to the clinical diagnosis and possible gastric extubation. Furthermore, the profile of the caregiver may positively or negatively affect the care of these patients. However, despite the identification of the problems and complications originating from the gastric intubation for HEN, there are few studies that explain the reality or explore the reasons which contribute to the replacement or removal of the tube, the types of extubation and the circumstances involved in these situations.

Given the above, this study aims: to characterize the sociodemographic profile of users and caregivers and the clinical diagnosis of the users who underwent gastric intubation for enteral nutrition in a Home Care Program (HCP); to classify the type of gastric extubation of these users; to determine the incidence of planned and unplanned gastric extubations; and to identify the reasons involved in the gastric extubation. 


\section{Method}

This is an exploratory-descriptive, quantitative study, with prospective data collection. The study site was a home care program of a university hospital of the municipality of São Paulo. The target population for this study was constituted by users who underwent gastric intubation for HEN. The exclusion criteria were defined as, users who evolved to death within the first 24 hours or those who had the route of feeding changed. Thus, 37 users were included in the study.

Data collection was performed from April 15 to August 15, 2010, using two forms. The first consisted of two parts: part I contains the demographic and clinical data of the users and the technical details of the procedure, recording the following variables: gender, age, the first three diagnoses, with that of the admission being considered as the principle and the second and third as secondary, the caregiver (gender, age, family or not, relationship and education), date of insertion of the tube under evaluation, route of insertion, type of diet, termination of the treatment (date and reason) and medication continuously administered via the tube. Part II of the form contained a table with columns for recording the reasons for withdrawal or replacement of the gastric tube. The second form was designed to measure the total of gastric intubation patients/day.

To select the subjects for possible inclusion in the study the electronic registration of users was consulted, indicating the patients with gastric intubation for enteral nutrition. Next, the medical records were searched and the data of the first part of the form were filled in by the researcher: "Patient History" and "Nursing Evaluation" contained in the records of the user. The data of the second part were recorded by the researcher or by the nurses of the HCP after the occurrence of the event. Also, the nursing notes and changes were referred to, especially in order to confirm the circumstances involved at the time of the extubation. The second form was completed by the researcher performing the calculation of the total intubated patients/day at the end of each month.

For the analysis of the qualitative variables the absolute and relative frequencies of the classes of each variable were used. For the quantitative variables means and medians, standard deviations, and minimum and maximum amplitude were employed, to indicate the variability of the data. To compare the means of the quantitative variables the chi-square test was used. The significance level adopted was $5 \%$ and the $p$ values $<0.05$.
The extubations were classified as planned, characterized by the completion of the therapy, by the elective replacement of the tube (according to the protocol, every 6 months) or change of the route of intubation (nasogastric for gastrostomy), and as unplanned extubations, characterized by the situation of removal of the tube due to rupture of the balloon, obstruction, deterioration of the material, and removal of the tube by the patient, healthcare professional or caregiver. The calculation of the incidence rate of planned and unplanned extubations occurred by applying the following equations:

\section{Incidence of extubation (Planned and Unplanned) =}

No. of extubations

Total patients/day c/ gastric intubation

Incidence of extubation (Planned) =

No. of planned extubations

Total patients/day c/ gastric intubation

\section{Incidence of extubation (Unplanned) =}

No. of unplanned extubations

Total patients/day c/ gastric intubation

$\times 100$

For all the phases of data collection of this study, a report detailing the methodology employed was submitted to the Department of Nursing and the Research Ethics Committee of the hospital, which was approved under protocol 986/10 and SISNEP CAAE 0013.0.198.000-10.

\section{Results}

Tables 1 and 2 describe the characterization of the 37 users and their respective caregivers.

Table 1 shows that in relation to gender, there was a predominance of females, 19 (51.4), and of the age group $\geq 60,25(67.6 \%)$. With regard to the admission diagnosis, it was found that the majority of the users presented disorders involving the neurological system, with 12 (33\%) presenting stroke and 10 (27\%) unspecified dementia. Neurological diseases usually cause loss of functional and cognitive capacity due to their natural progression, which leads the patient to dependence regarding the activities of daily living, such as eating, moving around and personal hygiene actions. Concerning the secondary diagnosis, 18 (48.7\%) 
Table 1 - Distribution of the users, according to the variables: gender, age group, admission diagnosis, secondary diagnosis. São Paulo, Brazil, $2010-\mathrm{N}=37$

\begin{tabular}{|c|c|c|}
\hline Variables & $\mathbf{N}$ & $\%$ \\
\hline \multicolumn{3}{|l|}{ Gender } \\
\hline Female & 19 & 51.4 \\
\hline Male & 18 & 48.6 \\
\hline \multicolumn{3}{|l|}{ Age Group (years) } \\
\hline $0|-| 18$ & 7 & 18.9 \\
\hline $18-160$ & 5 & 13.5 \\
\hline$\geq 60$ & 25 & 67.6 \\
\hline \multicolumn{3}{|l|}{ Admission Diagnosis } \\
\hline Stroke & 12 & 32.5 \\
\hline Unspecified Dementia & 10 & 27 \\
\hline Traumatic brain injury & 3 & 8.1 \\
\hline Cerebral Palsy & 3 & 8.1 \\
\hline Werdnig-Hoffmann Disease & 2 & 5.4 \\
\hline West Syndrome & 2 & 5.4 \\
\hline Malignant Neoplasms & 2 & 5.4 \\
\hline Chromosomal Abnormalities & 2 & 5.4 \\
\hline Immunodeficiency virus disease & 1 & 2.7 \\
\hline \multicolumn{3}{|l|}{ Secondary Diagnosis * } \\
\hline Pressure ulcers & 18 & 48.7 \\
\hline Systemic Arterial Hypertension & 7 & 18.9 \\
\hline Stroke & 4 & 10.8 \\
\hline Malignant Neoplasms & 1 & 2.7 \\
\hline Hepatitis C & 1 & 2.7 \\
\hline Others & 3 & 8.1 \\
\hline
\end{tabular}

* 3 users did not present a secondary diagnosis.

patients presented pressure ulcers and 7 (18.9\%) arterial hypertension.

Regarding the most used medication, the use of the drugs of the anticonvulsive/neuroleptic class (18\%) was observed, followed by a $13 \%$ use of antihypertensives, corresponding to the principle admission diagnoses and secondary diagnosis of hypertension. It should be clarified that $18.9 \%$ of the users received four or more medications and $5.4 \%$ did not make use of any drugs.

In the analysis of Table 2, it was found that the majority of the caregivers were female, 33 (89.2\%), and in the age group 18 to 60 years, 27 (73\%). Regarding their relationship with the user it was observed that 36 $(97.3 \%)$ were family members; $10(27 \%)$ represented by the mother, followed by the spouse, 9 (24.3\%). In relation to age, this ranged from 23 to 77 years, with the mean being 50.6 years $(S D \pm 13.4)$ and the median 49 years. Concerning education level, $35.1 \%$ had not concluded elementary education.

In relation to the time the users spent in the HCP of this study, this corresponded to a mean of 10.3 months $(S D \pm 12.2)$, minimum value of 0.1 (3 days) and a
Table 2 - Distribution of the caregivers, according to the variables: gender, age group, relationship and degree of relatedness. São Paulo, Brazil, $2010-\mathrm{N}=37$

\begin{tabular}{lcc}
\hline Variables & N & $\%$ \\
\hline Gender & 33 & 89.2 \\
$\quad$ Female & 4 & 10.8 \\
$\quad$ Male & & \\
Age Group (years) & 27 & 73.0 \\
$18|-| 60$ & 10 & 27.0 \\
$\geq 60$ & & \\
Relationship & 36 & 97.3 \\
Family & 1 & 2.7 \\
Non-family & & \\
Degree of Relatedness & \\
Mother & 10 & 27.0 \\
Spouse & 9 & 24.3 \\
Child & 8 & 21.6 \\
Sibling & 2 & 5.4 \\
Other relationship & 7 & 18.9 \\
\hline
\end{tabular}

*one caregiver had no family relationship.

maximum of 51 months. It was found that $56.8 \%$ of the users continued in monitoring and $43.2 \%$ were discharged from the program.

Regarding the reasons for discharge, the majority (69\%) left the HCP due to death, and $19 \%$ due to transfer to another service. There was also one patient ( $6 \%)$ who received administrative discharge for not adhering to the treatment, refusing to allow visits by the multidisciplinary team. The users who were discharged due to improvement or to another service (Primary Health Unit), were excluded from the study because they were not under the care of the HCP team.

It was identified that $51.4 \%$ had gastrostomy as the route of insertion of the tube. The semi-homemade diet (diet manipulated in the residence + industrialized nutritional supplement) was used by $51.4 \%$ of the users; the homemade diet by $45.9 \%$ and $2.7 \%$ made use of the industrialized diet.

The sum total of the days of gastric intubation of the users during the collection period amounted to 2676 days, with 745 days in the first month (total of 28 patients), 666 in the second ( 25 patients), 632 days in the third (23 patients) and 633 in the fourth month (22 patients).

As regards the mean length of permanence of the gastric tube, the value of 3.86 months was observed and a median of 4.16 months. This result is represented in Figure 1, below.

In analyzing Figure 1 , it was observed that the probability of a patient remaining with the gastric tube in the first month was $79.5 \%$. In the third month, the probability of the tube remaining was $55.5 \%$. The mean duration of 


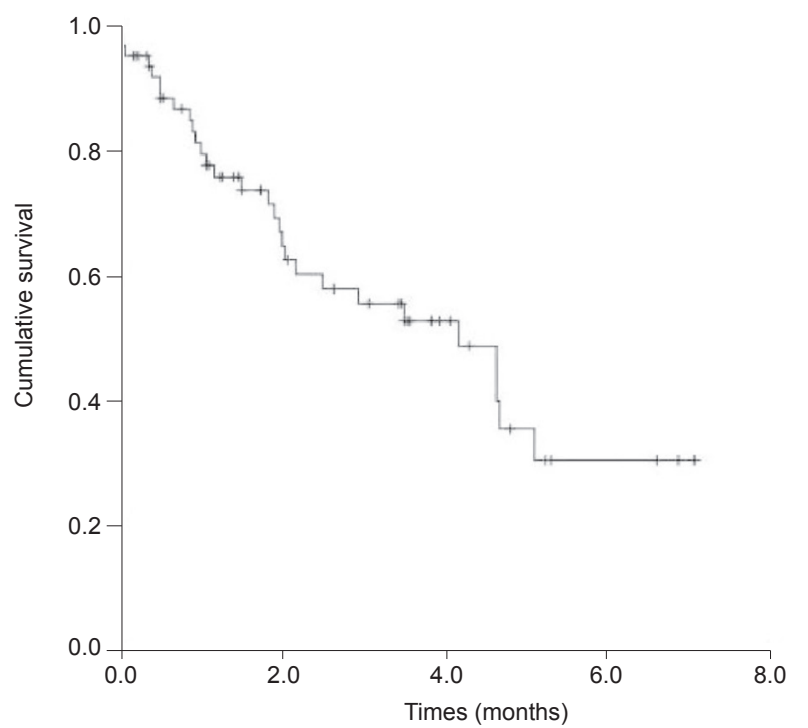

$\neg$ Survival functions

+ Censored

Figure 1 - Survival curve of the gastric intubation in the users. São Paulo, Brazil, 2010

the tube according to the route of insertion was 3.6 months for the nasogastric and 4.1 months for gastrostomy, with a median of 2.1 months and 4.1 months, respectively. It is noteworthy that at the start of the data collection, there were users with the tube already inserted, which were then evaluated from the day of its insertion.

During this study, it was noted that $51 \%$ of the users underwent extubations during the four months they were monitored. Regarding the extubations, nine users presented one extubation, seven presented two extubations and two users presented three, totaling 29 extubations, of which $75.8 \%$ were classified as unplanned, i.e. characterized by situations in which the events occurred under unexpected circumstances, and $24.2 \%$ as planned.

According to Table 3, the main reason for the planned

Table 3 - Distribution of the extubations according to type and the circumstances involved. São Paulo, Brazil, 2010 $-\mathrm{N}=29$

\begin{tabular}{lcc}
\hline Extubations & $\mathbf{N}$ & $\%$ \\
\hline Planned extubation & 4 & 13.8 \\
$\quad$ Elective replacement of the tube & 3 & 10.4 \\
Change of the route (nasogastric for gastrostomy) & 0 & 0.0 \\
$\quad$ Termination of the therapy & & \\
Unplanned extubation & 10 & 34.5 \\
Rupture of the balloon & 1 & 3.5 \\
Obstruction of the tube & 1 & 3.5 \\
$\quad$ Deterioration of the material & 2 & 6.8 \\
Selective position of the tube & 6 & 20.7 \\
$\quad$ Spontaneous withdrawal by the patient & 2 & 6.8 \\
$\quad$ Spontaneous withdrawal by the caregiver & 29 & 100 \\
\hline Total
\end{tabular}

extubations was the elective replacement of the tube, 4 $(13.8 \%)$, and for the unplanned extubations the majority (34.5\%) corresponded to the rupture of the balloon (device present only in the gastrostomy tubes), followed by spontaneous withdrawal $(20.7 \%)$ by the patient.

The following are the outcome indicators measured in this study: incidence rate of overall extubations, incidence rate of planned extubations and incidence rate of unplanned extubations.

Table 4 highlights that the third month showed the highest incidence of overall extubation (1.73), with 0.94 for the unplanned and 0.79 for the planned. The lowest incidence rate, of 0.31 , occurred in the fourth month. Applying the Chi-square test $(p=0.0093)$, a statistically significant difference was found between the planned and unplanned extubations. It is specified that in the first month 11 extubation occurred, 5 in the second, 11 in the third and 2 extubations in the fourth month.

Table 4 - Incidence rate by type of extubation of the users. São Paulo, Brazil, 2010

\begin{tabular}{ccccc}
\hline $\begin{array}{c}\text { Type } \\
\text { Month }\end{array}$ & $\begin{array}{c}\text { Planned } \\
\mathbf{N}=\mathbf{7}\end{array}$ & $\begin{array}{c}\text { Unplanned } \\
\mathbf{N}=\mathbf{2 2}\end{array}$ & Total & p-value \\
\hline 1 & 0.13 & 1.34 & 1.47 & \\
2 & 0.15 & 0.62 & 0.77 & \\
3 & 0.79 & 0.94 & 1.73 & $0.0093^{*}$ \\
4 & 0 & 0.31 & 0.31 & \\
Total & 0.26 & 0.80 & 1.07 & \\
\hline
\end{tabular}

*Chi Square test

\section{Discussion}

Home care leads to the recognition of the domicile as a possible and effective care space. In it, the dynamic of the care processes are involved, which include the evaluation and adaptation of the physical space, the planning of the care and the guidance to those responsible for the patient.

The results of this study related to the variables gender, age and primary diagnosis are similar to the studies performed in the characterization of the users of a program of home care ${ }^{(15-16)}$, in which users were predominant in the age range $\geq 60(67.6 \%)$ and of the female gender (51.4\%). Regarding the primary diagnosis, of the 37 users, $59.5 \%$ presented diseases involving the neurological system, in agreement with a similar study with patients who received $\mathrm{HEN}^{(17)}$.

In $\mathrm{HC}$ the practice of medication administration via the tube takes place, due to the clinical conditions of the patient or the impossibility of using the oral or parenteral route. A mechanical complications of gastric intubation is the obstruction of the nasogastric tube, which can be 
related to the retention of residues of the enteral formula in its lumen, as a result of the high osmolarity; the formation of insoluble formula-medication complexes; inadequately macerated tablets injected by the tube, and precipitation of the formula due to the acidity of the gastric contents ${ }^{(18)}$

The chronic-degenerative diseases often require special care because the patient becomes dependent or semi-dependent for self-care. To meet this need the figure of the caregiver arises, which, in the majority of cases, is a family member or someone close to the patient.

Regarding the profile of the caregivers, this consisted in the majority of females (89.2\%), and $27 \%$ were over 60 years of age, demonstrating the increasing trend of elderly people providing care to other elderly people, which can lead to problems with the caregiver's own health status. The degree of relatedness is represented by $24.3 \%$ of spouses, $21.6 \%$ of children and $18.9 \%$ with other links. These data are similar to those found in another study ${ }^{(15)}$.

Concerning the route of insertion of the gastric tube, studies performed in European countries, such as Italy and France, show the main route of insertion and administration of HEN to be gastrostomy. However, in Spain, this route was used for $25 \%$ of the population undergoing $\operatorname{HEN}^{(9)}$. Another study found that $83 \%$ of the patients received the diet by gastrostomy ${ }^{(19)}$. In Brazil a study reported that $61.8 \%$ of the patients received enteral nutrition in the domicile, via the nasogastric tube(20). This is explained by the variability in relation to the choice of intubation route for HEN, since this depends on the clinical condition of the patient, on the availability of resources of the service, and on the family members/user choosing the access route.

Gastric extubations can be considered as health evaluation measures, especially when they generate healthcare indicators. However, it was observed that there is little published work in the literature monitoring the proportion, the incidence rate and the reasons or circumstances involved in this event, and when studies have been performed the authors have chosen to study unplanned extubations.

A study conducted in the hospital environment, recording adverse events in relation to nasogastric tubes, central venous catheters, endotracheal tubes, medication errors and falls, found that those related to nasogastric tubes, represented $57.6 \%$ of the total, demonstrating a greater demand for attention by the nursing team in the handling and care of this device ${ }^{(21)}$.

Another study, carried out with a retrospective collection of data in an intensive care unit for adults located in Sao Paulo, found that the rates of unplanned extubation ranged from 0.13 to $0.22^{(22)}$. However, they attributed the low incidence of extubation of the nasogastric tube to the fact that they had only measured the extubations in which reintubations were necessary, excluding the events related to the migration of the tube. Within the sphere of $\mathrm{HC}$ no studies were found regarding extubations, limiting the comparability of the findings of the present study.

The importance of the nurses in the HCP is emphasized, considering the important role they play and their presence in all the steps of care of the users undergoing HEN, influencing greatly the success of therapy, such as in the satisfaction of the users and family members.

\section{Conclusions}

This study has made it possible to know the reality of the healthcare practice of gastric intubation for nutritional support of the users attended in a home care program of a university hospital and to recognize that the success of the therapy involves a set of technical, ethical and social knowledge which needs to be apprehended by the healthcare professionals involved in domicile care. This set of knowledge is represented by the human resources quantitatively and qualitatively trained in the choice of materials and establishment of care protocols, including the insertion, fixation, manipulation and maintenance of the gastric tube. Also, it is important to offer guidance and training to the user or caregiver regarding the manipulation of the gastric tube and other associated activities such as: the preparation and administration of the diet and medication, the recognition of complications and the referrals needed for each situation.

Regarding the profiles of the users and caregivers it was found that this study is in agreement with the findings of the literature, represented by the expansion of the services of $\mathrm{HC}$, above all to assist the elderly population or children and adolescents dependent on technology. The calculation of the incidence rate of gastric extubation in this study was made possible through the application of the output indicator of the Donabedian Model(13), with the higher incidence of unplanned extubations due to the rupture of the balloon, in the case of the patients with gastrostomy, or withdrawal of the tube by the users. Concerning the first reason, there is a need to verify aspects involving the type and brand of the material, the manipulation of the tube by the caregiver, the psychomotor agitation of the patient, maintenance of regular training programs and evaluation of the practice of learning on the part of the caregiver. In relation to the second reason, the need exists to pay attention to the attachment of the probe, to observe psychomotor agitation and to reorient 
the caregivers/family members in order to minimize the complications arising from these types of extubation.

Consequently, the context of home care is a field of knowledge to be explored, since it constitutes a global trend in health management and the use of indicators allows the identification of real and potential problems, in order to implement effective actions to achieve quality in healthcare.

\section{References}

1. World Health Organization (WHO). Home-based and long-term care: home care issues and evidence. Geneva: WHO, 1999. [acesso 10 março 2009]. Disponível em: http://www.who.int/chp/knowledge/publications/ Chronic_conditions/en/index. html.

2. Hirschfeld MJ, Oguisso T. Visãopanorâmica da saúde no mundo e a inserção do home care. RevBrasEnferm. 2002;55(4):452-9.

3. Fabrício SCC, Wehbe G, Nassur FB, Andrade JI. Home care: the experience of a private hospital in the state of São Paulo. Rev. Latino-Am. Enfermagem. 2004;12(5):721-6.

4. Dal Ben LW, Gaidiznski RR. Proposta de modelo para dimensionamentodopessoal deenfermagememassistência domiciliária. RevEscEnferm USP. 2007;41(1):97-103.

5. Oguisso T, Schmidt MJ. Exercício da Enfermagem domiciliária (Home Care). In: Oguisso T, Schmidt MJ. O exercício da enfermagem: uma abordagem ético-legal. $3^{a}$ ed. Rio de Janeiro: Guanabara Koogan; 2010. p. 197-206. 6. Dal Ben LW, Gaidzinski RR. Sistema de classificação de pacientes em assistência domiciliária. Acta Paul Enferm. 2006;19(1):100-8.

7. Duarte YAO. O cuidador no cenário assistencial. MundoSaúde. 2006;35(4):56-63.

8. Planas M, Pérez-Portabela C, Rodrigues T, Pruggiós C, Elvira D, Daalman E. Evalución del grado de satisfacción de un programa de nutrición enteral domiciliaria. NutrHosp. 2007;22(5):612-5.

9. Moreno-Vilares JM. La práctica de la nutrición artificial domiciliaria in Europa. NutrHosp. 2004;19(2):59-67.

10. Paccagnella A, Baruffi C, Pizzolato D, Favaro V, Marcon $M L$, Morello $M$, et al. Home enteral nutrition in adults: a five-year (2001-2005) e epidemiological analysis. Clin Nutr. 2008;27:378-85.

11. Costa HMC, Luz MOR, Carmona MJC, Cardoso E, Isosaki M, Auler JOC Júnior. Reintrodução da alimentação oralempacientestraqueostomizadoscomterapia de nutrição enteral. RevBrasNutrClin. 2003;18(4):168-72.

12. Donabedian A. Evalución de la calidad de la atención médica: In: White KL, Frank J, organizadores. Investigacionessobreservicio de salud: uma antologia. Washington (DC): OPAS; 1992. p. 382-404.
13. Donabedian A. The methods and findings of quality assessment and monitoring: an illustrated analysis. Michigan: Health Administration Press, 1985.

14. Joint Commission on Accreditation of Healthcare Organizations. Accreditation Characteristics of clinical indicators.QRB Qual Rev Bull. 1989;15(11):330-9.

15. Yamaguchi AM, Higa-Taniguchi KT, Andrade L, Bricola SAPC, Jacob-Filho W, Martins MA. Assistência domiciliar: uma proposta interdisciplinar. São Paulo: Manole; 2010.

16. Chayamiti EMRE, Caliri MHL. Úlcera por pressão em pacientes sob assistência domiciliar. Acta Paul Enferm. 2010;23(1):29-34.

17. Cawsey SI, Soo J, Gramlich LM. Home enteral nutrition: outcomes relative to indication. NutrClin Practice. 2010;25(3):296-300.

18. Matsuba CST, Gutiérrez MGR, Whitaker IY. Development and evaluation of standardized protocol to prevent nasoenteral tube obstruction in cardiac patients requiring enteral nutrition with restricted fluid volumes. J Clin Nurs. 2007;16(10):1872-7.

19. Best $\mathrm{C}$, Hitchings $\mathrm{H}$. Enteral tube feeding - from hospital to home. Br J Nurs. 2010;19(3):174-9.

20. Zaban ALRS, Novaes MRCG. Demographic, epidemiological and nutritional profile of elders in home enteral nutritional therapy in Distrito Federal, Brazil. Invest Clín. 2009;50(2):347-57.

21. Nascimento CCP, Toffoletto MC, Gonçalves LA, Freitas WG, Padilha KG. Indicators of healthcare results: analysis of adverse events during hospital stays. Rev. Latino-Am. Enfermagem. 2008;16(4):746-51.

22. Cartolano FC, Caruso LC, Soriano FG. Terapia nutricional enteral: aplicação de indicadores de qualidade. Rev Bras TerIntensiva. 2009;21(4):376-83. 